\title{
AGV SYSTEMS - AUTONOMOUS VEHICLES IN METALLURGY
}

\author{
Jan BŘEZINA, Hana ŠPAČKOVÁ, Martin MENŠíK \\ VSB - Technical University of Ostrava, Ostrava, Czech Republic, EU, \\ jan.brezina.st@vsb.cz
}

https://doi.org/10.37904/metal.2019.785

\begin{abstract}
Target of this contribution is description of implementation and using autonomous vehicles (AGV) in metallurgy plants. Currently is trend doing focus on automatization of production processes due to degreasing costs and due to missing workers as well. To the total production process we can include logistics like important part it means transport of materials or semi-finished product from point $A$ to point $B$ for example between minority production processes. Currently AGV systems are expanding to the others production plants but it has to be calculated that technology of AGV system need to be adapted a modified according using and according environment where will be AGV system implemented. Contend of this contribution is especially description of technical specification AGV system to heavy industry with focus on metallurgy processes. Technical description will focus for using sensor equipment which is part of autonomous control and it serves like picker of data and information system about vicinity in real time. In this contribution will clarify specification of drive which will be atypical for the metallurgy industry. In article will be mentioned question of safety in cases approaching people to AVG system direct touch or even problem with collision with physical objectives, which is placed in area permanently or temporary.
\end{abstract}

Keywords: Metallurgy, AGV, autonomous, systems, process

\section{INTRODUCTION}

Currently, the trend of using autonomous vehicles is on the rise. From simple autonomous vehicle, for example, that are driven by the simple programming like mowers, to fully self-driving cars that are filled with sensors, camera markers and radar cameras to scan nearby objects. These cars can already be met on the road in the face of several years. However, autonomous road vehicles have to be almost $100 \%$ reliable to avoid possible collisions with other objects that are also members of the transport system. I want to say that a very reliable technology for transporting objects from $A$ to $B$ is fully developed and not secret. Some companies, especially in the automotive industry, are already publicly exposing and bragging about their know-how about autonomous technology.

Companies are constantly trying to save money according the trend. They adapt to the current world situation and invest considerable resources in automation of logistics systems in order to reduce personnel costs. These automated logistics systems, or if you want autonomous logistics systems are used in the automotive industry to transport material flow between production processes. Thus, they ensure, for example, the transport of the inlet parts or semi-finished products from point $A$ to point $B$ as required by the process.

AGV systems are slowly but surely implemented in every industry and time is coming to become an integral part of heavy industry, especially metallurgical processes.

In Metallurgy, logistics is a very complicated system between individual production processes. Metallurgy logistics includes, for example, the transport of materials, the transport of semi-finished products to another production process, eg billets for rolling mills, where wire or rods are rolled. If we were to analyze this process in detail. The billets, which are either cast or cut, undergo a control and "cleaning" process in the cleaning process themselves, are moved by a magnetic crane to a massive roller conveyor through which billets are metered for inspection and cleaning. The billets, which are slowly cooled down and waiting for tansport to the 
rolling mills, where they are reheated and rolled, for example, in a rod, which is then transported somewhere again. By optimizing and automating the logistics process, we can prevent, for example, heat loss, not being dependent on human capacity and human labor, avoiding the human factor and, ultimately, saving the labor costs that we know are not small at all. Such optimization can be exploited by the aforementioned AGV systems already used in the world in heavy industry.

Although this use of autonomous vehicles seems to have only the same advantages, it is necessary to take into account the excessive servicing, recharging or powering of these vehicles. It is also necessary to take into account some fleet for possible parking, construction of some infra-structure, eventually area for parking of autonomous vehicles. So in this case there is no direct art that what is fully automatic is better at all costs. An investment plan is needed to cover all costs, ie. Both technology acquisition costs and fixed and flexible operating costs. Of course, we have to deduct from the cost of saving items for the personnel we would physically lose by this upgrade. Each company determines the return period of its investment itself. In most cases, the payback period is about two years, with AGV, which is very expensive, the return period is usually greater than two years. If the company has the ambition to be fully automated in the future, without AGV technology, it is very difficult to bypass, most companies are now switching to automated systems and AGV systems are the kind of automation that can be most easily implemented into the plant and difficult, such as in the production process robotics, since AGV systems have been designed from the outset to avoid objects in the hall, put great emphasis on safety, avoid collisions with humans, and effectively perform the assignment according to a clear definition and adaptation of a given AGV system..

\section{LOAD HANDLING}

One of the first important features in choosing the AVG type for the metallurgical process is handling. The type of construction must be adapted to allow easy loading and unloading of the required material. The material must also be securely fixed after loading. Currently, robotic arm is most commonly used for loading and unloading material, but the condition is to stop the AGV at the same place with high accuracy at all times. Another popular method is to adjust the AGV's seat surface to a roller or belt track. However, the material must be stored in a crate, carrier, or container for transport. The advantage of these AGV conveyors is a simple connection to any roller system. The AGV therefore arrives at a defined position where it connects to a conveyor system. It is unlocked, optionally decanted. The conveyor drive on the AGV is started to move the material to the required position and location. Another and easiest way to load and unload material is through human power. In this case, however, the transport time depends on the free capacity and speed of the man's handling. Another problem, particularly in metallurgical processes, is that in the vast majority of cases it is the handling of heavy loads, or generally the handling of large weights. Another big downside is the emergence of an occupational disease that can affect employees for handling. The cost of eventual treatment for the employee may be on exorbitant amounts.

\section{APPLIED NORMS / DIRECTIVES}

The following norms and directives apply to the product and have to be met by the manufacturer (InSystems Automation $\mathrm{GmbH}$ ).

\subsection{Guidelines}

Machinery Directive 2006/42/EC

EMV-guideline 2004/108/EG

\subsection{AGV Standards}

DIN EN 1525:1997 Driveless industrial trucks and their systems 
DIN EN ISO 3691-4 Industrial trucks - Safety requirements..

DIN EN 1175-1 Safety of industrial trucks - Electrical requirements-

Part 1: General requirements for trucks with electric battery drive

VDI 2510 Automated Guided Vehicle Systems (AGVS)

VDI 2710 Interdisciplinary design of automated guided vehicle systems (AGVS)

VDI 4452 Acceptance specification for automated guided vehicle systems (AGVS)

\subsection{Design and Safety Standards}

DIN EN ISO 12100-1 Safety of machinery - General principles for designDIN EN ISO 13849-2 Safety of machinery - Safety-related parts of control systems

DIN EN ISO 13857 Safety of machinery - Safety distances to prevent hazard zones being reached by upper and lower limbs

DIN EN 349 Safety of machinery - Minimum gaps to avoid crushing of parts of the human body

DIN EN 614 Safety of machinery - Ergonomic design principles

DIN EN 61310 Safety of machinery - Indicators, flashing and control - part 1: requirements for visible, audible and tactile signals

\subsection{Electric and EMC Standards}

DIN EN 60204 Safety of machinery - Electrical equipment of machines/ DIN VDE 0113-XXX Electrical equipment of machines

DIN VDE 0100 Low-voltage electrical installations to $1000 \mathrm{~V}$

DIN EN 50274/VDE0660-514 Low-voltage switchgear assemblies - Protection against electric shock Protection against unintentional direct contact with dangerous active parts

DIN EN 61000-6-2 Electro Magnetic Compatibility (EMC) - Parts 6-2: Generic standards - Immunity for industrial environments

Non-Contact Protective Devices Standards

DIN EN 61496 Safety of machinery - Non-contact protective devices - Part 1: General requirements and tests

\subsection{Professional Association}

DGUV regulation 3 - Accident Prevention Regulations Electrical Installations and Equipment

DGUV regulation 68 - loaders

\subsection{Laws}

ASR 1.8 Technical rules for workplaces - traffic routes

\section{TECHNICAL SPECIFICATION}

General desription of technical specifications should define basic information about AGV systém a his physical properties and which technical elements have to be used for our target where exactly we want to implement AGV system showed in Table 1. 


\begin{tabular}{|c|c|}
\hline Technical element & example \\
\hline Dimensions & $\mathrm{L} 2500 \mathrm{~mm} \times \mathrm{W} 2000 \mathrm{~mm}$ \\
\hline Type of scan for scanning enviroment & SICK 5300 \\
\hline Positioning technology & $\begin{array}{l}\text { Localization and Mapping with laser scanner, and } \\
\text { gyroscopit sensor }\end{array}$ \\
\hline Max speed & $1,5 \mathrm{~m} / \mathrm{s}$ \\
\hline Positioning accuracy & $\begin{array}{l}\text { in normal drive } 2^{\circ},+/-3 \mathrm{~cm} \text {, after reference drive } 1^{\circ},+/- \\
2 \mathrm{~cm}\end{array}$ \\
\hline Load & up to $400 \mathrm{~kg}$ \\
\hline Height of load transfer & 800 to $1400 \mathrm{~mm}$ \\
\hline Battery & $\begin{array}{l}\text { LiFeYPO4 with balancing boards and temperature } \\
\text { monitoring }\end{array}$ \\
\hline Battery life & $3-5$ years \\
\hline Driving/charging ratio & $5: 1$ \\
\hline Certfications & CE- certified for interaction with humans \\
\hline Communication & WLAN \\
\hline
\end{tabular}

Table 1 example of technical specification of AGV system

\section{SAFETY FUNCTIONS}

AGVs have to be safe to colaborate with humans, It means that the AGV have to fully work together with factory workers without the need of implementing safety fences and bariers.

AGV interact and travel should be on the same path as peoples. AGV has to including some protective fields showed in Figure 1. When some person will entre to AGV fields, AGV has to speed down and starts to drive around person. In technical combination of SICK and Laser scanner is possible to dynamically adapt the field"s sizes and than adapt speed of AGV. It could be very helpful to avoid obstacles or stop motions.AGV has to have emergency „STOP“ buttons on good places for fast stop of this device.

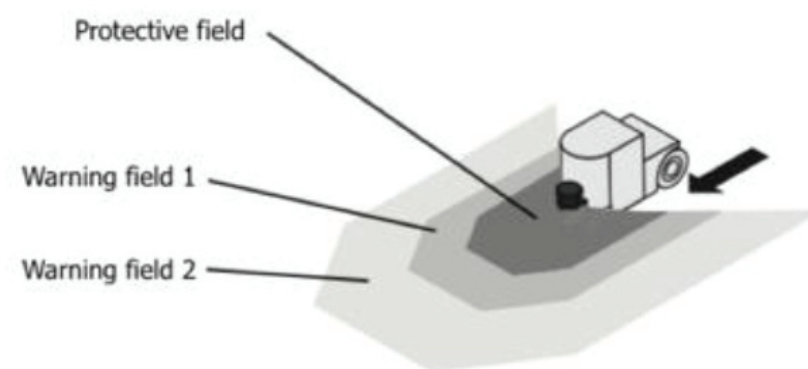

Figure 1 Loading handling with roller conveyor

\section{NAVIGATION}

The AGV could be navigated direcly for using factory's layout. A laser scanner integrated into the vehicle measures the distance between the vehicle and its surroundings.

The first set-up is mostly one robot from the fleet and moved around the manually, for example by the joystick. all distance profiles from the laser scanner could be recorded and combined with the data from the motor encoders. This creates a map that reflects the contours of the objects scanned by the scanner. This map can 
be read from the robot and manually edited. A graphical editor can be used to add one-way passages, pathfree areas, and destination locations to the map.

At start up, the robot starts with its initial location to determine its current location. This can be achieved by comparing the currently received distance profile with the laser scanner with a coherent fraction of the map. During an autonomous operation, the localization algorithm can be triggered at regular intervals, allowing the robot to continuously realize its own location in the mapped area. [1] [2]

\section{CONTROL SIGNALS, BATTERY AND CHARGING STATION}

For the AGV communicating with enviroment should be integrated into the AGV. Very important part of AGV are warning signals for example lights, acoustic sounds, which are warning for some situation which came. Very helpfull can be integration panel where can robot show currently status about all important information.

Very important is useing type of battery, how long we need to have avaiable AGV systém, how offen per day we can charge it. The same topic is batery charger. Need to be define where exactly will be "docking station"

Which power supply we will exactly need. It means voltage and fused. [3]

\section{IMPLEMENTATION OF AGV SYSTEMS IN METALLURGY}

As a logistics facility used to transport eg products, goods or materials from point $A$ to point $B, A G V$ systems can be used in modern metallurgical operations mainly for the transport of semi-finished products that have already undergone a metallurgical process, such as transport of lamps, sheets, or bars from the manufacturing process to the warehouse showed in Figure 2. It is mostly a material that is dosed in a lower weight category. When implementing an AGV into the production process, load and unload handling must be considered. Nowadays it is quite common to automatically manipulate with the help of forks, which material without any control of the man picking up the material, transport to the destination and automatically unloads from the fork (this method is used eg in automotiv industry), then back to the starting point and the entire cursor are repeated automatically. Of course, AGV systems can also be used for the transport of raw materials (coke, coal, slagforming, iron ore, scrap) in the metallurgical complex, in principle all AGV systems work the same; a massive design for heavy loads, or a drive that also has a higher output. Although this variant is more expensive than train transport, unlike train transport, it can bring the raw materials into place even where there are no tracks. For better tracking of AGV and Materials as well can be used wireless RFID Tags. [4]

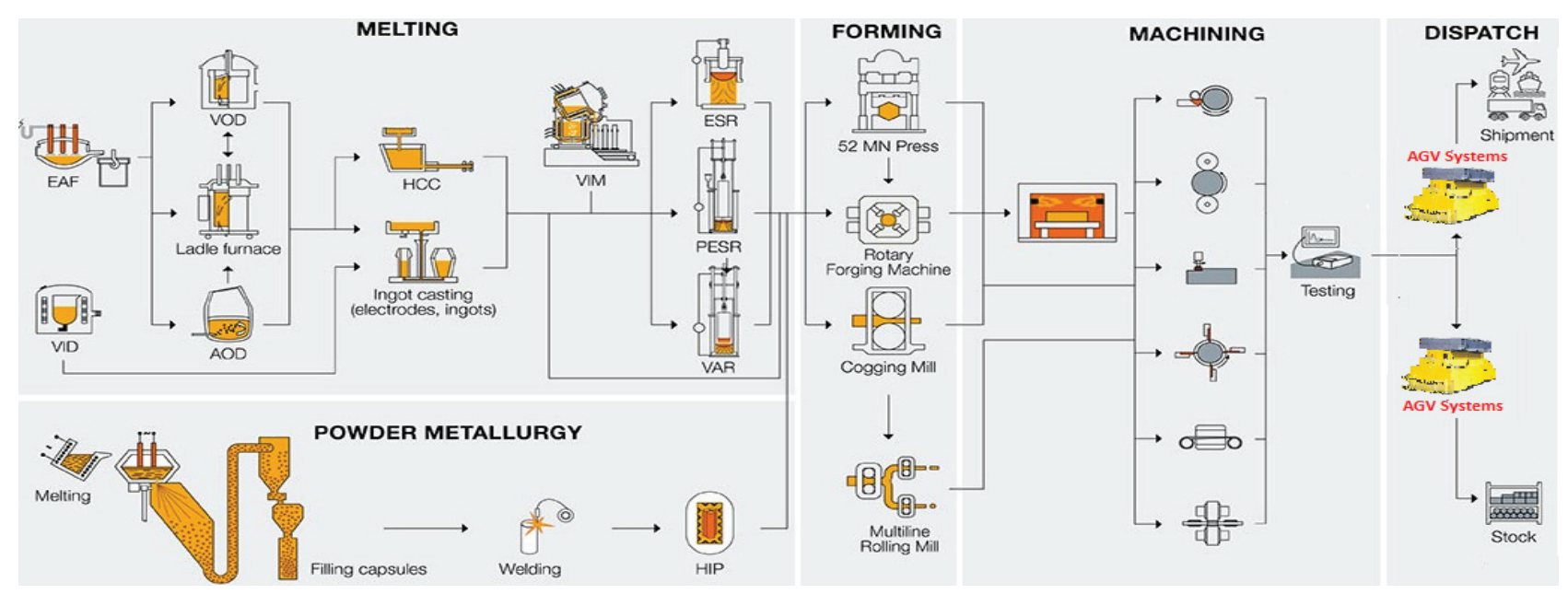

Figure 2 Diagram of metallurgy proceses where is implemented AGV system 
The application of the AGV system in the metallurgical industry can also be used in interprocess logistics. For example, in the process of "cleaning" long billets. In "cleaning", the billets are unloaded from the transport and then the billet surface is machined, eg. by blasting, then the billets undergo a visual inspection to indicate visible cracks. The billets are then moved under a grinder where the surface is ground by the marking. The billets are then prepared for transport, for example, to a rolling mill. Throughout the "clean-up" process, several logistical shifts of billets occur, using the AGV system, the billets do not have to be manually transported to every "clean-up" process site, all you need to do is load the billets on the AGV and the AGV will automatically go through each treatment plant. [5]

\section{CONCLUSION}

The future of metallurgical logistics processes lies in the automation of the logistics nodes, for example, with the help of AGVs. The AGV must be designed according to the idea of use. This issue should be approached with great caution and especially with the help of specialists who are familiar with the subject in detail. The choice of the most optimal technology for AGVs should be mediated by the firm's investment plan, where a compromise is sought between investment and the use of the AGV.

\section{ACKNOWLEDGEMENTS}

The work was supported by the specific university research of Ministry of Education, Youth and Sports of the Czech Republic No. SP2019/17 and SP2019/62 and company ITeuro s. r. o.

\section{REFERENCES}

[1] DAVID, J., SVEC, P. and R. FRISCHER. Support for maintenance and technology control on slab device of continuous casting. In: METAL 2013: 22nd INTERNATIONAL CONFERENCE ON METALLURGY AND MATERIALS. Ostrava: Tanger, 2013, pp. 1650-1655.

[2] DAVID, J., POLLAK, M. and TUHY, T. Modern communication technologies usage for controlling metallurgical processes. In: METAL 2014: 23RD INTERNATIONAL CONFERENCE ON METALLURGY AND MATERIALS. Ostrava: Tanger, 2014, pp. 1678-1683.

[3] KREJCAR, O. and R. FRISCHER. Real Time Voltage and Current Phase Shift Analyzer for Power Saving Applications. SENSORS. 2012, 12 (8), pp. 11391-11405.

[4] DAVID, J., FRISCHER, R. and M. STRANAVOVA. Usage of rfid wireless identification technology to support decission making in steel works. In: METAL 2012: 21st INTERNATIONAL CONFERENCE ON METALLURGY AND MATERIALS. Ostrava: Tanger, 2012, pp. 1734-1738.

[5] SVEC, P., L. FRISCHEROVA and J. DAVID. Usage of clustering methods for sequence plan optimization in steel production. METALURGIJA. 2016, 55 (3), pp. 485-488. 